\title{
Bonding properties and crystallization kinetics of thermoplastic polyurethane adhesive
}

\author{
Geovana de Avila Bockorny ${ }^{1-2}$, Núbia Liziani Preuss ${ }^{3}$, \\ Carmem Rosane Isse Gomes ${ }^{3}$, Nei Sebatião Domingues Junior ${ }^{1}$, \\ Maria Madalena de Camargo Forte ${ }^{1}$
}

\footnotetext{
${ }^{1}$ Federal University of Rio Grande do Sul (UFRGS), Engineering School, Laboratory of Polymeric Materials (LAPOL), Ave. Bento Gonçalves 9500, P.O. Box 15010, CEP: 91501-970 Porto Alegre, Rio Grande do Sul, Brazil.

${ }^{2}$ Artecola Indústrias Químicas Ltda, Industrial Zone 2, CEP: 93700-000 Campo Bom, Rio Grande do Sul, Brazil.

${ }^{3}$ SENAI Institute for Innovation in Polymer Engineering, Ave. Presidente João Goulart, 682, CEP: 93030-090 São Leopoldo, Rio Grande do Sul, Brazil.

e-mail: geovana.bockorny@artecola.com.br, mmcforte@ufrgs.br, nei_domingues@hotmail.com,

nubia.preuss@senairs.org.br, carmem.gomes@senairs.org.br
}

\begin{abstract}
The advantages of heterophasic thermoplastic polyurethanes (TPUs), such as their phase behavior and mechanical properties, make these materials an important class of adhesives. Whereas the amorphous phase contributes to good adhesion properties, the crystalline phase is responsible for the cohesive force of TPU adhesives. This work investigates the performance of a polyester based TPU and its potential for being applied as adhesive in the shoe industry. The TPU was formulated with three different additives. The crystallization kinetics of the TPU was evaluated by Differential Scanning Calorimetry and the Avrami equation was used to assess the influence of the additives on the geometry of crystal growth and nucleation conditions. It was found that the additives had no effect on the nucleation process, whereas the polymer chains had reduced mobility, mainly in the TPU comprising polyisocyanate $\varepsilon$-caprolactam. The best T-peel strength on a poly(vinyl chloride) (PVC) substrate was determined for the TPU with polycarbodiimide, which improved the adhesive bonding from $3.23 \mathrm{~N} / \mathrm{mm}$ to $3.32 \mathrm{~N} / \mathrm{mm}$.
\end{abstract}

Key words: TPU, polyurethane, polycarbodiimide, adhesive, crystallinity.

\section{INTRODUCTION}

Thermoplastic polyurethanes (TPUs) are an important class of thermoplastic and thermosetting polymers due to their mechanical, thermal, chemical and adhesive properties, which can be defined through the proper combination of a huge variety of polyols and isocyanates building blocks. These characteristics are related to the polymer's structure, soft and hard segment content, block length and chemical compatibility between the soft and hard segments. One can obtain polyurethane structures ranging from homogeneous to phase separated ones. Typically, two-phase morphology consists of hard domains with polar properties, and an amorphous soft phase having a relatively low glass transition temperature $\left(\mathrm{T}_{\mathrm{g}}\right)$. The hard domains act as physical crosslinks to the soft matrix, and elastomeric properties are observed in TPUs with relatively low hard domain contents $[1,2]$

Phase separation affects the physical and mechanical properties of a TPU, e.g. its hardness and elasticity modulus, abrasion resistance and strength resistance. This micro-phase separation is determined by competitive hydrogen bonding between different segments and the crystallization of hard segments. BISTRIČIĆ et al. [3] identified in their studies no distinctive influence of nanoparticles on the glass transition temperatures of soft segments, while the effect of nanosilica on the melting behavior of the hard phase was observed only in the samples with higher hard segment content.

The TPU solvent based adhesive was introduced in the shoe industry 70 years ago. ADSUAR [2] stud 
ied several polyurethane solvent adhesives and found that the composition of TPUs influences their morphology and properties. An increase in the hard segments content in TPUs reduces the degree of phase separation and the organization of hard domains, resulting in less crystalline polymers with worse adhesion properties.

Therefore, it is important to know the crystallization characteristics of TPUs in order to improve their bonding performance. TSAI et al. [4] studied the crystallization of poly(lactic acid) (PLA), varying some processing parameters, such as stretch ratio, heat setting temperature, and heat setting time, and found that the optical and mechanical properties as well as the dimensional stability of the resulting polymer films were governed by their crystallinity.

A TPU hot melt adhesive is a thermoplastic polymer that has been developed to reduce the volatile organic compounds in the industrial environment. The amorphous phase of the TPU hot melt is responsible for polymer flexibility and the crystalline phase for its cohesive strength.

In this work, the use of additives in a TPU hot melt adhesive was investigated with the aim to improve the adhesion properties, using PVC as a standard substrate. According to standard ISO 20344:2004, the peel strength reference values for upper/sole adhesion in footwear designed for babies, children, women and men are: $\geq 2 \mathrm{~N} / \mathrm{mm}, \geq 4 \mathrm{~N} / \mathrm{mm}, \geq 3 \mathrm{~N} / \mathrm{mm}$ and $\geq 4 \mathrm{~N} / \mathrm{mm}$, respectively [5]. In the shoe industry, the adhesive properties are paramount to ensure the quality of footwear [6].

The adhesives were produced and used in powder form, as an alternative for conventional solvent based polyurethane adhesives with a view to reduce the use of volatile organic compounds in the shoe industry. Adhesion properties were investigated by T-peel strength tests, and DSC thermal analysis was also performed.

\section{MATERIALS AND METHODS}

According to the supplier's information, the characteristics of the thermoplastic polyurethane used in the experiments (in pellet form) were as follows: polyester based polyurethane, with viscosity (15\% methyl ethyl ketone - MEK) of $1800 \mathrm{cPs} ; \mathrm{T}_{\mathrm{g}}$ of $-42{ }^{\circ} \mathrm{C}$; number average molecular weight (Mw) of $10.000 \mathrm{~g} / \mathrm{mol}$; and Ring and Ball $(\mathrm{R} \& \mathrm{~B})$ temperature of $44^{\circ} \mathrm{C}$.

Additive A: Polycarbodiimide: Mw: $3300 \mathrm{~g} / \mathrm{mol}$; density $\left(20^{\circ} \mathrm{C}\right): 1.05 \mathrm{~g} / \mathrm{cm}^{3} ; \mathrm{R} \& \mathrm{~B}: 60-90^{\circ} \mathrm{C}$.

Additive B: Hydrocarbon resin: $\mathrm{Mw}: 50 \mathrm{~g} / \mathrm{mol}$; acidity $\left(\mathrm{KOH} \mathrm{mg} / \mathrm{g}\right.$ ) less than $0.1 ; \mathrm{T}_{\mathrm{g}}: 50^{\circ} \mathrm{C} ; \mathrm{R} \& \mathrm{~B}$ : $105^{\circ} \mathrm{C}$.

Additive C: $\varepsilon$-caprolactam blocked polyisocyanate: Isocyanate (NCO) content: 12.8-15.7(\%); $\mathrm{T}_{\mathrm{g}}: 41$ $53^{\circ} \mathrm{C}$; R\&B: $62-82^{\circ} \mathrm{C}$.

\subsection{Formulation}

Table 1 shows the compositions of the adhesives. The components in powder form were physically mixed in a $0.5 \mathrm{~L}$ reactor (at environmental temperature and under low shaking). The concentration of the additives was based on the indications of the respective suppliers.

Table 1: TPU adhesive formulations.

\begin{tabular}{l|l|l|l|l}
\hline Component /Sample (\%) & TPU & TPUA & TPUB & TPUC \\
\hline TPU & 100 & - & - & - \\
\hline Additive A & 99 & 1 & - & - \\
\hline Additive B & 96 & - & 4 & - \\
\hline Additive C & 95 & - & - & 5 \\
\hline
\end{tabular}




\subsection{Differential scanning calorimetry (DSC)}

Calorimetric data were obtained by DSC with a TA DSC Q100, according to ASTM D3418-12ع1. Experiments were carried out using approximately $5.5 \mathrm{mg}$ of sample, in a sealed aluminum pan. The samples were heated up to $80^{\circ} \mathrm{C}$ at a rate of $10^{\circ} \mathrm{C} / \mathrm{min}$ to erase their thermal history and then cooled to $-50^{\circ} \mathrm{C}$ to find out the crystallization temperature $\left(\mathrm{T}_{\mathrm{c}}\right)$ and enthalpy $(\Delta \mathrm{Hc})$. Then, the samples were heated again to $80^{\circ} \mathrm{C}$ to record the melting temperature $\left(\mathrm{T}_{\mathrm{m}}\right)$ and enthalpy $(\Delta \mathrm{Hm})$.

Equation 1 was used to calculate the crystalline fraction $(\mathrm{Xc})$ of the adhesives, using the melting enthalpy values measured herein and the enthalpy values for $100 \%$ crystalline TPU, as reported in the literature [7].

$X c=(\Delta H m \div \Delta H 100 \%) \times 100$

$$
\Delta \mathrm{H}_{100 \%}=196.8 \mathrm{~J} / \mathrm{g}[7]
$$

\subsection{Isothermal Crystallization}

The isothermal crystallization behaviors of the samples were investigated using a TA DSC Q100 thermal analyzer. All of the samples were melted at $80^{\circ} \mathrm{C}$ for $5 \mathrm{~min}$ to eliminate any previous thermal history, then rapidly cooled to the designated crystallization temperatures $\left(\mathrm{T}_{\mathrm{c}}\right)$, ranging from 26 to $28^{\circ} \mathrm{C}$, and maintained at that temperature for $30 \mathrm{~min}$ to complete the whole crystallization process.

The Avrami equation was applied to determine the geometry of crystal growth and the nucleation conditions. Relative crystallinity (Xt) was obtained using the following Equation 2:

$X t=\int_{t 0}^{t}\left(\frac{d H c}{d t}\right) d t / \int_{t 0}^{t \infty}\left(\frac{d H c}{d t}\right) d t$

Where $t 0$ and too are time parameters denoting when crystallization begins and ends, respectively, dHc represents the change of enthalpy during an infinitesimal time range dt around time t.

\subsection{Peel Strength Test}

The tests were carried out using PVC specimens according to ABNT NBR 10456:2012 - Adhesives for Footwear and Resistance Bonding [8]. Injection molded samples had a Shore A hardness of $75 \pm 5$ Shore A; and the following dimensions: $30 \pm 1 \mathrm{~mm}$ width, $160 \pm 2 \mathrm{~mm}$ length and $3 \pm 1 \mathrm{~mm}$ thickness. The steps taken for surface preparation and bonding of the PVC material described in Table 2.

Table 2: Bonding process

\begin{tabular}{l|l}
\hline Steps & Treatments \\
\hline 1 & $\begin{array}{l}\text { Clean the PVC material - Ketone solvent } \\
\text { base }\end{array}$ \\
\hline 2 & Apply primer on the PVC surface \\
\hline 3 & $\begin{array}{l}\text { Apply powder adhesive (TPU) in a spray } \\
\text { form }\end{array}$ \\
\hline 4 & Melt the adhesive (temperature $\left.70-75^{\circ} \mathrm{C}\right)$ \\
\hline 5 & $\begin{array}{l}\text { Apply pressing force of } 222 \mathrm{~N} \mathrm{during} 12 \\
\text { seconds }\end{array}$ \\
\hline 7 & Allow 72 hours rest \\
\hline 8 & Peel at a $180^{\circ}$ angle \\
\hline
\end{tabular}


9

Samples

\section{RESULTS}

This section presents the results obtained from thermal analysis, as well as the findings regarding the crystallization kinetics and the peel strength of the samples under study.

\subsection{Thermal evaluation of TPU}

Figure 1 illustrates the thermal fusion analysis for the investigated samples of adhesives. It may be remarked that, both for the neat TPU sample and for its mixtures with the three additives (TPUA, TPUB, and TPUC), the melt temperature $\left(\mathrm{T}_{\mathrm{m}}\right)$ shows a single endothermic peak.

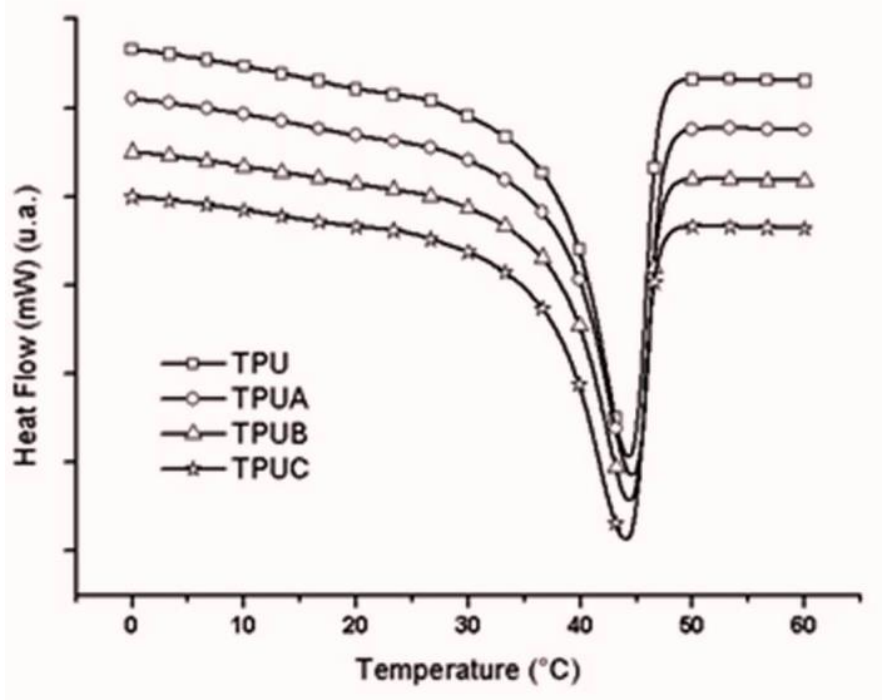

Figure 1: $\mathrm{T}_{\mathrm{m}}\left({ }^{\circ} \mathrm{C}\right)$ of polyurethanes with different additives

Figure 2 presents the cooling curves of the studied samples, and allows identifying the crystallization temperatures $\left(\mathrm{T}_{\mathrm{c}}\right)$.

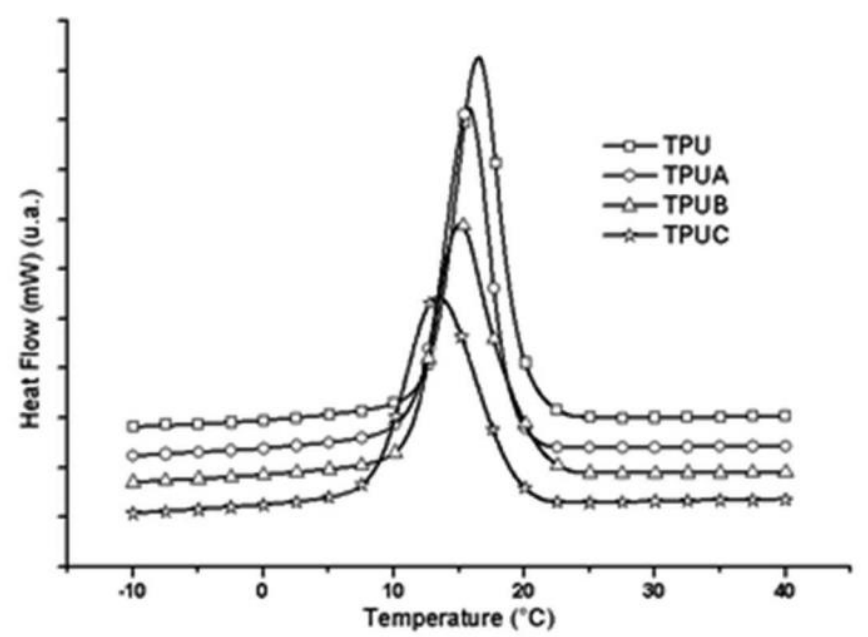

Figure 2: $\mathrm{T}_{\mathrm{c}}\left({ }^{\circ} \mathrm{C}\right)$ of TPU adhesives 
The calculated results for the crystalline fractions are tabulated in Table 3. The low crystallinity of all the formulations suggests a significant amorphous fraction for the base polymer [9].

Table 3: Thermal parameters obtained from the DSC curves of adhesives

\begin{tabular}{l|l|l|l|l|l}
\hline & & & & & \\
Sample & $\mathrm{T}_{\mathrm{m}}\left({ }^{\circ} \mathrm{C}\right)$ & $\mathrm{T}_{\mathrm{c}}\left({ }^{\circ} \mathrm{C}\right)$ & $\Delta \mathrm{Hm}(\mathrm{J} / \mathrm{g})$ & $\Delta \mathrm{Hc}(\mathrm{J} / \mathrm{g})$ & $\mathrm{Xc}$ \\
\hline TPU & 44 & 16 & 32.8 & 34.7 & $17 \%$ \\
\hline TPUA & 45 & 16 & 34.1 & 35.5 & $17 \%$ \\
\hline TPUB & 44 & 15 & 33.4 & 35.0 & $17 \%$ \\
\hline TPUC & 44 & 13 & 31.3 & 31.5 & $16 \%$ \\
\hline
\end{tabular}

$\mathrm{T}_{\mathrm{m}}$ : Melting temperature; $\mathrm{T}_{\mathrm{c}}$ : Crystallization temperature; $\Delta \mathrm{Hm}$ : Enthalpy of fusion; $\Delta \mathrm{Hc}$ : Enthalpy of crystallization; Xc: crystalline fraction.

\subsection{Crystallization Kinetics}

A series of isothermal crystallization data obtained from the DSC analysis of polyurethane with different additives ( $\mathrm{A}, \mathrm{B}$ and $\mathrm{C}$ ) were used to determine the relative crystallinity $(\mathrm{Xt})$. Figure 3 presents the sigmoid curve of TPU crystallization on time in various isothermal processes. 

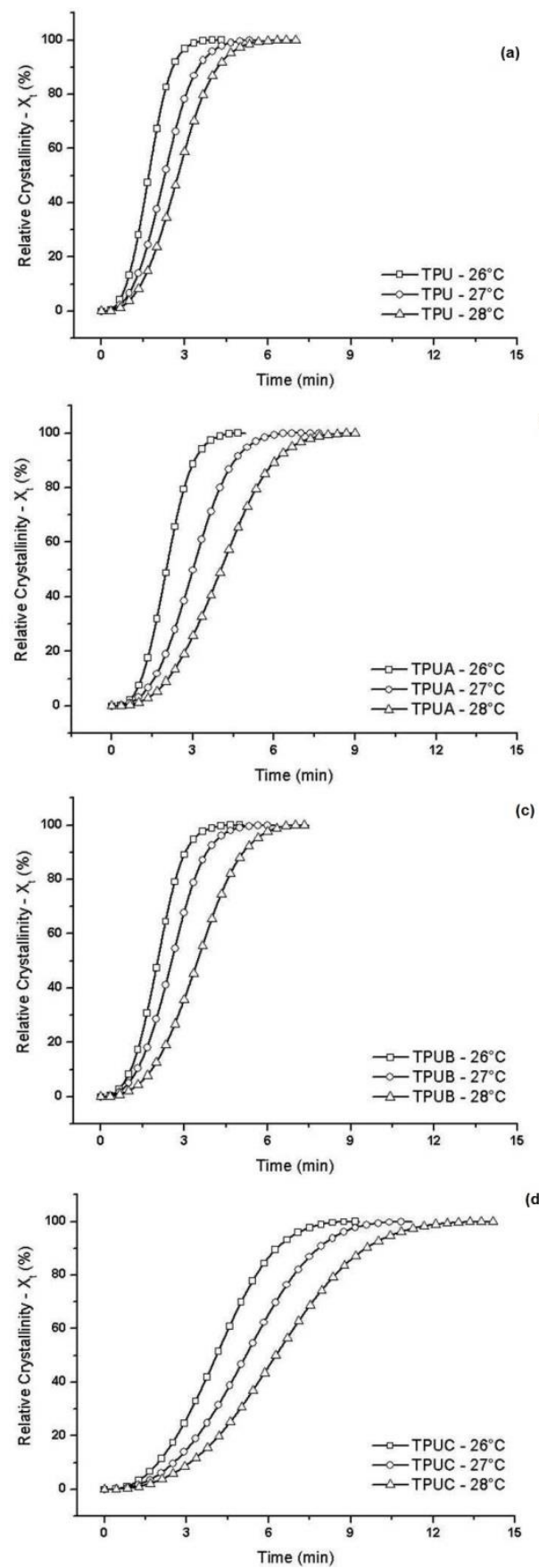

Figure 3: Relative crystallinity as a function of time: a) TPU, b) TPUA, c) TPUB, d) TPUC

Figure 4 depicts the behavior of pure TPU and its mixtures after thermal treatment at three different crystallization temperatures $\left(26,27\right.$ and $\left.28^{\circ} \mathrm{C}\right)$. 

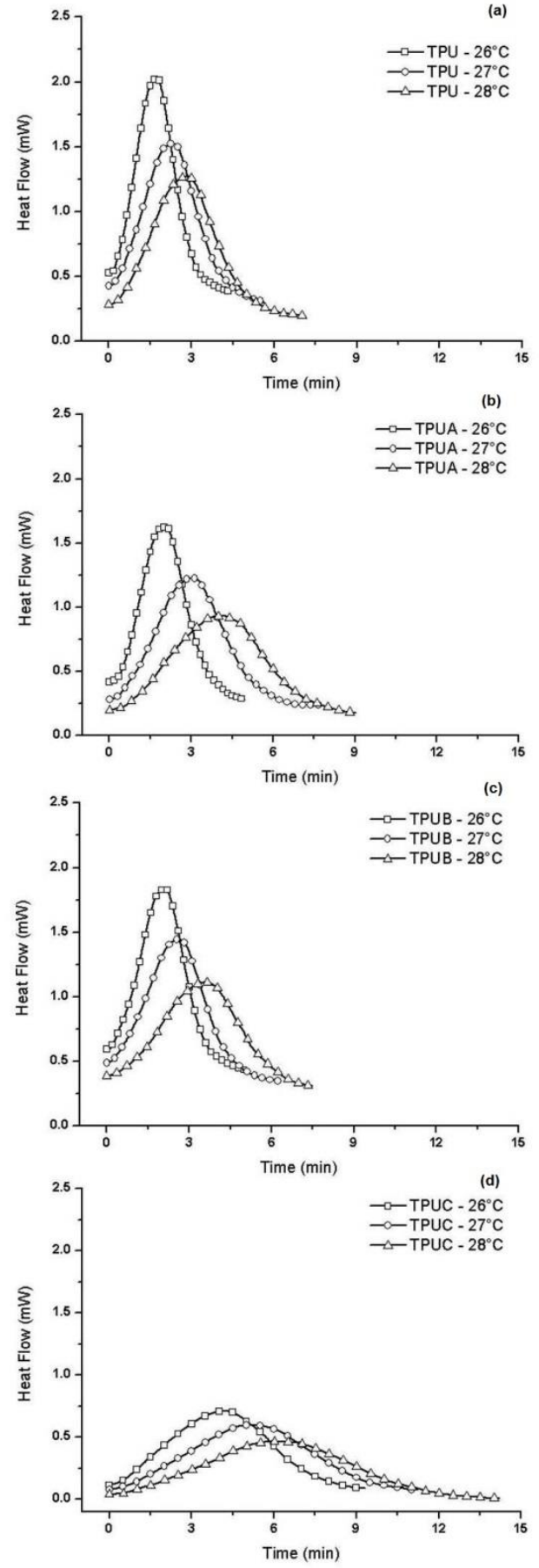

Figure 4: Heat flow at different isothermal temperatures (26, 27 and $\left.28^{\circ} \mathrm{C}\right)$ : a) TPU, b) TPUA, c) TPUB, d) TPUC.

Figure 5 shows the linear fit used to obtain the Avrami kinetic parameters for pure TPU and the formulations containing additives. 


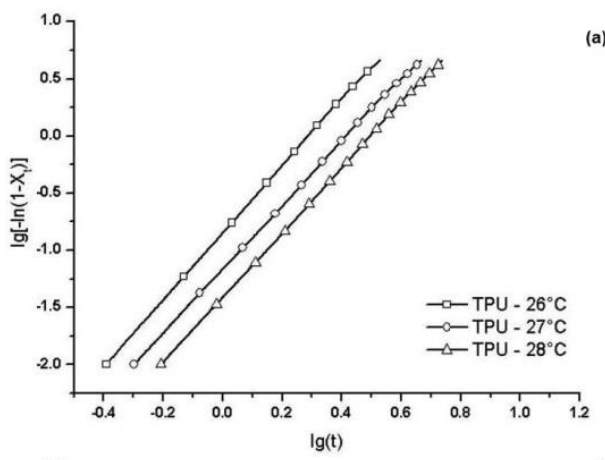

(a)

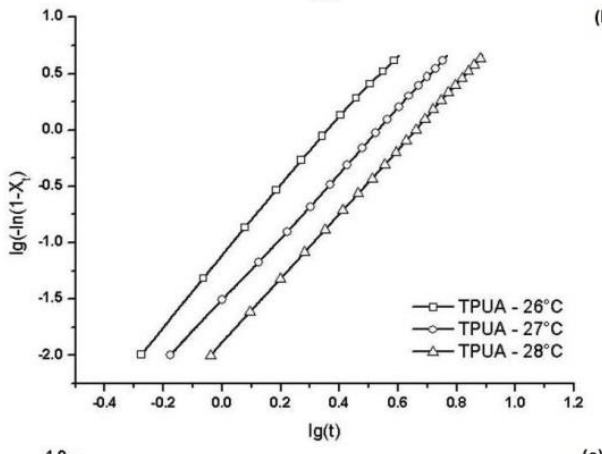

(b)
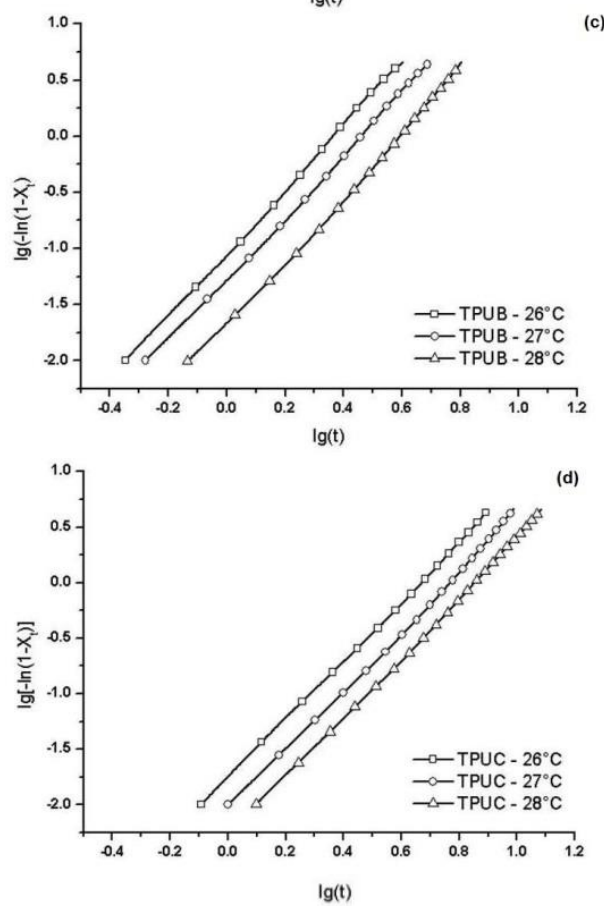

Figure 5: Plot of $\lg [-\ln (1-\mathrm{Xt})]$ versus $\lg (\mathrm{t})$ for isothermal crystallization: a) TPU, b) TPUA, c) TPUB, d) TPUC.

The TPU crystallization kinetics was evaluated and the effect of additives was systematically investigated. Table 4 lists the crystallization half-time values for pure TPU and the TPU formulations with additives, for the calculated and experimental results. 
Table 4: Crystallization half-time for pure TPU and its formulations with additives A, B and C

\begin{tabular}{c|c|c|c}
\hline \multirow{4}{*}{ Sample } & Temperature $\left({ }^{\circ} \mathbf{C}\right)$ & $\mathbf{t}_{\mathbf{1} / \mathbf{2}}$ Experimental (min) & $\mathbf{t}_{\mathbf{1} / \mathbf{2}}$ Calculated (min) \\
\cline { 2 - 4 } & 26 & 1.71 & 1.74 \\
\cline { 2 - 4 } & 27 & 2.28 & 2.30 \\
\hline \multirow{4}{*}{ TPUA } & 28 & 2.76 & 2.77 \\
\cline { 2 - 4 } & 26 & 2.03 & 2.06 \\
\cline { 2 - 4 } & 28 & 3.01 & 3.00 \\
\hline \multirow{3}{*}{ TPUB } & 26 & 4.04 & 3.97 \\
\cline { 2 - 4 } & 27 & 2.05 & 2.50 \\
\cline { 2 - 4 } & 28 & 2.56 & 2.66 \\
\hline \multirow{3}{*}{ TPUC } & 26 & 3.48 & 3.35 \\
\cline { 2 - 4 } & 28 & 4.06 & 3.96 \\
\hline
\end{tabular}

$\mathrm{t}_{1 / 2}:$ crystallization half-time

In Table 5, the kinetic values obtained from the Avrami study for pure TPU and its mixtures are shown.

Table 5: Kinetic values for adhesive TPU1 and additive formulations

\begin{tabular}{c|c|c|c|c|c|c|c}
\hline TPU1 & $\mathrm{n}$ & $\mathrm{K}$ & $\mathrm{R}^{2}$ & TPU1 B & $\mathrm{n}$ & $\mathrm{K}$ & $\mathrm{R}^{2}$ \\
\hline $26^{\circ} \mathrm{C}$ & 2.96 & 0.135 & 0.9989 & $26^{\circ} \mathrm{C}$ & 2.77 & 0.089 & 0.9908 \\
\hline $27^{\circ} \mathrm{C}$ & 2.79 & 0.068 & 0.9996 & $27^{\circ} \mathrm{C}$ & 2.78 & 0.046 & 0.9899 \\
\hline $28^{\circ} \mathrm{C}$ & 2.83 & 0.039 & 0.9999 & $28^{\circ} \mathrm{C}$ & 2.61 & 0.030 & 0.9972 \\
\hline $\mathbf{T P U 1} \mathbf{A}$ & $\mathrm{n}$ & $\mathrm{K}$ & $\mathrm{R}^{2}$ & $\mathbf{T P U 1} \mathbf{C}$ & $\mathrm{n}$ & $\mathrm{K}$ & $\mathrm{R}^{2}$ \\
\hline $26^{\circ} \mathrm{C}$ & 2.90 & 0.085 & 0.9965 & $26^{\circ} \mathrm{C}$ & 2.66 & 0.018 & 0.9979 \\
\hline $27^{\circ} \mathrm{C}$ & 2.61 & 0.046 & 0.9954 & $27^{\circ} \mathrm{C}$ & 2.59 & 0.011 & 0.9938 \\
\hline $28^{\circ} \mathrm{C}$ & 2.63 & 0.019 & 0.9974 & $28^{\circ} \mathrm{C}$ & 2.71 & 0.005 & 0.9983 \\
\hline
\end{tabular}

\subsection{Peel Strength Test}

The peel strength values of neat TPU and its mixtures with additives are presented in Figure 6. 


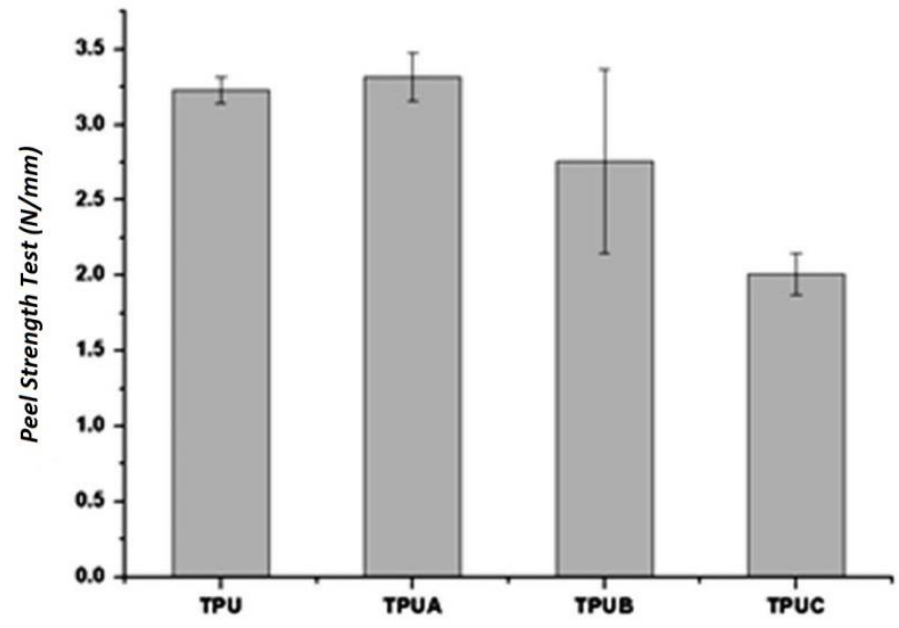

Figure 6: Peel strength values for the TPU adhesive and its mixtures with different additives

\section{DISCUSSION}

It is critical to understand the correlation between the thermal behavior of an adhesive and its bonding properties. Therefore, the samples were submitted to DSC analysis in order to study their crystallization kinetics and peel resistance, to identify the formulation with the highest potential to be used as a thermoplastic adhesive for shoe soles.

Figure 1 reveals acceptable characteristics of the TPUs due to the homogeneity of the formulations [7]. However, a clear difference in heat flow is observed in the formulations with additives, compared to that of neat TPU, indicating a decreasing trend of the heat flow values. The melt temperature behavior is directly related to the reactivation temperature for the peel resistance measurement. The TPU adhesive compositions were reactivated from 70 to $75^{\circ} \mathrm{C}$ per 1 minute, and according to the DSC thermograms, this temperature range was suitable for achieving a complete melt $\left(\mathrm{T}_{\mathrm{m}}\right.$ between 44 and $\left.45^{\circ} \mathrm{C}\right)$ and the penetration of the adhesives into the substrate.

The TPU and the additive mixtures (TPUA, TPUB, and TPUC) showed a single crystallization peak, according to Figure 2. Both the crystallization onset temperature and the heat flow were lower for all the formulations comprising additives, when compared with pure TPU. FERRAGE et al. [10] also described the use of DSC for the study of non-isothermal crystallization kinetics, where the curves showed the effect of adding $0.5 \%$ nucleating agent to $\mathrm{PP}$ at a cooling rate of $5 \mathrm{~K} / \mathrm{min}$. The addition of $0.5 \%$ nucleating agent significantly increased the onset of crystallization temperature. Nonetheless, in the present study, the presence of the additives led to an opposite effect.

Another important finding of the present investigation is the peak broadening in the curves corresponding to the TPU formulations $\mathrm{B}$ and $\mathrm{C}$. The peak broadening could be explained by the restriction of polymer chain movement, caused by the presence of the additives. The same effect was identified by MORALES et al. [11]. Enthalpy data were normalized with respect to the actual mass of the polymeric matrix in the samples.

As regards the thermal properties of the investigated formulations, the thermal parameters listed in Table 3 reveal no significant differences between the values of the pure TPU and those of the formulations including additives. Thus, it may be concluded that the additives had no effect on the evaluated thermal properties. $\mathrm{T}_{\mathrm{m}}$ was not affected, indicating little to no interaction between the additives and the hard segments of TPU, as opposed to the findings of SHIOMI et al. [12], who reported differences in crystallinity for poly(tetrahydrofuran)-polystyrene diblock copolymers (PTHF-PS). 


\subsection{Crystallization Kinetics}

As expected, the crystallization rate decreased as the crystallization temperature increased, due to greater mobility of the polymer chains [13]. All the curves had S-like shapes and they were linear from 10 to $90 \%$ in the S-like regions. Moreover, according to Figure 3, the greater the slope in the linear portions, the higher the crystallization rate is. Usually, at the beginning of crystallization, the nucleation of crystallites decreases the crystallization rate, whereas at the end of crystallization, the adjacent crystallite restricts spherulites growth [14].

In the graphics of Figure 4, one can observe a longer crystallization time and a reduction in the crystallization rate as the isothermal crystallization temperature increases. This trend was also identified by MORALES et al. [11] in a study on PP and its compounds with organoclay. Figure 4 also indicates an increase of the crystallization time with the use of the additives, which is most obvious for the formulation with additive C. MORALES et al. [11] attributed the slower crystallization rates to the restriction of polymer chain movement.

Figure 5 shows the linear fit used to obtain the Avrami kinetic parameters for the neat TPU and the formulations containing additives (A, B and C). The crystallization kinetics of TPU was evaluated and the effect of the additives was systematically investigated.

The crystallization half-time is the time required for $50 \%$ of the crystallization process to occur. [15, 16] It is a very important crystallization kinetics parameter and it has been used to characterize the crystallization rate directly, the longer the $t_{1 / 2}$, the slower the crystallization rate [17]. The crystallization half-time values are tabulated in Table 4. The calculated values were obtained using Equation 3, and a comparison with the experimental DSC results for the studied temperature range $\left(26^{\circ} \mathrm{C}, 27^{\circ} \mathrm{C}\right.$ and $\left.28^{\circ} \mathrm{C}\right)$ indicates a strong correlation. The $t_{1 / 2}$ increased with the use of all three additives, most significantly with additive $\mathrm{C}$ (Polyisocyanate $\varepsilon$-caprolactam). The increase in isothermal temperatures also determined an increase in the $t_{1 / 2}$.

$$
\mathrm{t} \frac{1}{2}=(\ln 2 \div \mathrm{k}) \frac{1}{\mathrm{n}}
$$

The crystallization rate for the TPU/additive mixtures is significantly lower than that of the neat TPU under lower isothermal crystallization temperature, implying that the additives are not effective as nucleating agents and the half-life increase could be related to the size of the crystals formed [15].

The results obtained by the Avrami equation exhibit a reduction of the $n$ values in the formulations including the additives A, B, and C, as shown in Table 5. The $n$ is the Avrami exponent, whose value is related to the mechanism of nucleation and the shape of crystal growth. The values of the Avrami exponent $n$ for pure TPU and for the formulations with the additives decrease with an increase in the temperature, suggesting changes in the type of nucleation and crystal geometries. The reduction in $n$ values indicates the interference of the additives in the crystal growth. The values of $n$ range from 2.59 to 2.96 , indicating threedimensional diffusion-controlled spherulitic crystal growth [17,18]. A lower $n$ value can be identified for sample TPUC, which is visible in Figure 4, where the evident isothermal broadening curve is characteristic of low spherulite formation.

The $n$ values for the pure TPU and its mixtures with the additives exhibited low variation, similarly to the melting variation, which shows a similar temperature for all the samples of adhesives. Furthermore, when the Avrami exponent takes fractionated values, this indicates differences in the surface of the samples, according to the $n$ value found for each powder adhesive tested [19].

As expected, the values for the rate constant $\mathrm{K}$ decreased with the increase in isothermal temperature and with the presence of additives, supporting the lack of nucleation effect in the studied formulations [20]. In a work on compounding $\mathrm{TiO}_{2}$ with $\mathrm{PP}$, Silva [21] noted an increase in $\mathrm{K}$ values, suggesting a high effect of nucleation kinetics. Nevertheless, in the present investigation, the presence of additives in the TPU led to opposite results.

The crystallization process was successfully described using the Avrami equation for all the TPU formulations under study, showing a good linear fit for the experimental data (linearization $R^{2} \geq 0.98$ ) [21], according to Figure 5 and Table 5. 


\subsection{Peel Strength Test}

Comparing the results from Figure 6 with standard values for peel strength (of $\geq 2 \mathrm{~N} / \mathrm{mm}, \geq 4 \mathrm{~N} / \mathrm{mm}, \geq 3$ $\mathrm{N} / \mathrm{mm}$ and $\geq 4 \mathrm{~N} / \mathrm{mm}$ in footwear designed for babies, children, women and men, respectively) according to PAIVA et al. [5], revealed that all the formulations achieved the minimum requirements for use in the shoe industry. The adhesives TPU $(3.23 \mathrm{~N} / \mathrm{mm})$ and TPUA $(3.32 \mathrm{~N} / \mathrm{mm})$ reached the standard values for adhesives for women's shoe sole attachment, while TPUB $(2.76 \mathrm{~N} / \mathrm{mm})$ and TPUC $(2.01 \mathrm{~N} / \mathrm{mm})$ could be used only for bonding baby shoes [6].

Adsuar [2] observed that the adhesion properties are worsened (i.e. smaller peel strength, cohesive failure) as the hard segments content in the TPU structure is increased, in accordance with a decrease in the degree of phase separation and structure organization.

The formulation with additive A, polycarbodiimide, presented higher peel strength results. This additive is typically used to improve hydrolysis resistance as a result of a reaction with alcohols and carboxyl groups created during the hydrolysis reaction [22]. The polycarbodiimide $(\mathrm{N}=\mathrm{C}=\mathrm{N})$ group reacts with the TPU's carboxylic groups $(\mathrm{COOH})$, improving the bonding performance, [23] as shown in Figure 7.

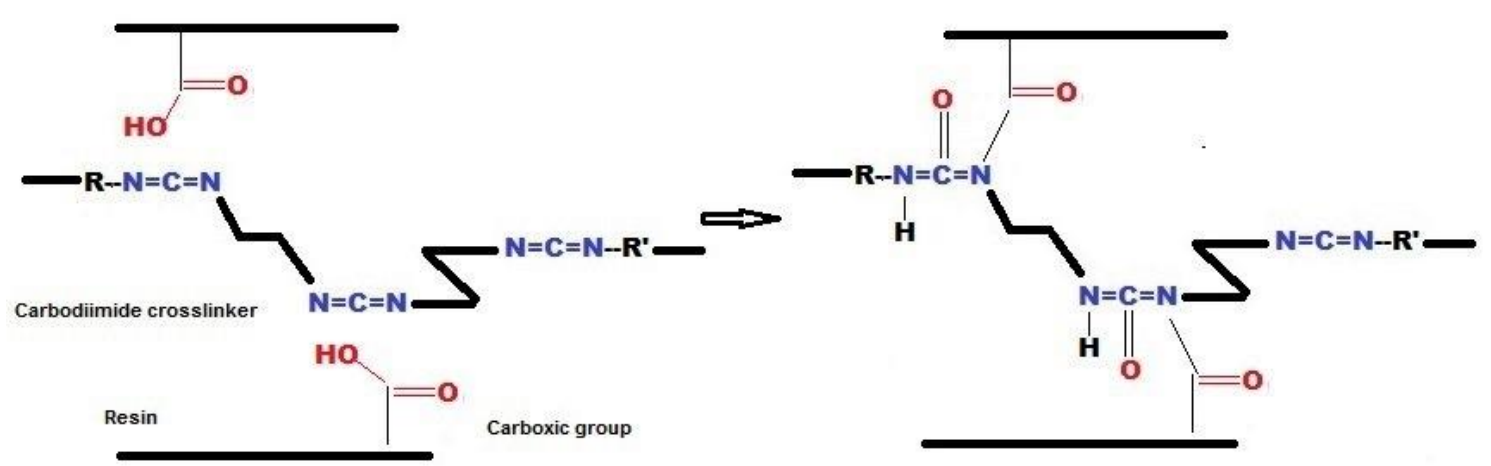

Figure 7: Reaction between polycarbodiimide and carboxic group.

The TPUB adhesive exhibited lower values for peel strength, when compared to the pure TPU polymer; this type of low molecular hydrocarbon resin is used in hot-melt adhesives to improve tack properties and reduce viscosity [24]. These features are necessary to control the penetration of the hot-melt adhesive into the substrate when applied in the molten state. In the present study, the adhesive was applied in powder form and therefore it had no effect in improving substrate penetration, consequently decreasing peel strength.

The formulation TPUC with $\varepsilon$-caprolactam capped polyisocyanate presented the lowest resistance among the adhesives under study. This chemical compound has an electrophilic carbon atom that is highly reactive towards the hydroxyl groups present in the TPU. Despite the higher reactivity, the isocyanate group released during the reaction is potentially harmful and could represent a serious drawback for potential applications [25]. The blocked isocyanate reaction occurs when the caprolactam is exposed to an activation temperature; the low peel strength results obtained suggested that the minimum temperature for the decoupling reaction to occur was not achieved.

ZHANG et al. [26] reported that TPU may accelerate or inhibit the crystallization of polyamide PA1010. In the case of the PA1010/TPU (98/2) blend, a small amount of TPU, as a nucleation agent, may be favorable for the formation of nucleus, resulting in PA1010 with a higher $T_{c}$. Increased TPU content increases the interaction between the two polymers, hindering PA1010 crystallization, and reducing $\mathrm{T}_{\mathrm{c}}$. In order to be effective, the nucleation agent needs good compatibility with the polymer, which involves wetting the heterogeneous additive. The nucleation agent must be insoluble in the polymer matrix and possess higher melting temperature [27]. The nucleating effect on polymer crystallization depends on several aspects, such as the size and geometry of the particles, the surface structure and interfacial interactions with the polymer matrix [20]. The study of the crystallization kinetics demonstrated that formulations $\mathrm{A}, \mathrm{B}$ and $\mathrm{C}$ presented increased $\mathrm{t}_{1 / 2}$, when compared to the pure TPU polymer, suggesting a poor nucleation effect. 


\section{CONCLUSIONS}

In the presence of additives, the TPU adhesive exhibits a reduction in spontaneous nucleation and growth. The crystallization kinetics revealed that more time was necessary for the crystallization process to occur in the presence of additives, indicating that these types of materials are not recommended to be used as nucleation agents.

The values calculated for the Avrami exponent $n$ ranged from 2.59 to 2.96, indicating a threedimensional diffusion-controlled spherulitic crystal growth. When the additives were used, the $n$ value decreased, because of the changes in the nucleation type and crystal growth geometry.

Polycarbodiimide (TPUA) rendered similar values of peel strength to those of the neat TPU, which allowed concluding that it may be suitable for use in bonding women's and babies' shoe soles. On the other hand, the formulation TPUC, which included the polyisocyanate additive, showed the lowest crystallinity and peel strength.

The results of the kinetic study point out the fact that a longer time is required for the crystallization of TPU in the presence of additives, compared to that of neat TPU. The sigmoidal curves observed for the formulation with additive $\mathrm{C}$ indicated the longest crystallization time and the lowest heat flow values among all the formulations under investigation, suggesting that the reduction in chain mobility in the formulation TPUC was more evident than that in the other adhesives.

\section{ACKNOWLEDGMENTS}

The authors would like to thank Artecola Química S.A.; ISI Polymer-SENAI; Science without Borders program from $\mathrm{CNPq}$ and FINEP.

\section{BIBLIOGRAPHY}

[1] CASTAGNA, A.M., FRAGIADAKIS, D., LEE, H., et al., "The role of hard segment content on the molecular dynamics of poly (tetramethylene oxide)-based polyurethane copolymers", Macromolecules, v.44, n.19, pp 7831-7836, Sep. 2011.

[2] SANCHEZ-ADSUAR, M. "Influence of the composition on the crystallinity and adhesion properties of thermoplastic polyurethane elastomers", International Journal of Adhesion and Adhesives, v.20, n.4, pp 291298, June 2000.

[3] BISTRIČIĆ, L, BARANOVIĆ, G, LESKOVAC, M, et al., "Hydrogen bonding and mechanical properties of thin films of polyether-based polyurethane-silica nanocomposites", Europe Polymer Journal, v.46, n.2, pp 1975-1987, Oct. 2010.

[4] TSAI, C-C, WU, R-J, CHENG, H-Y, et al., "Crystallinity and dimensional stability of biaxial oriented poly(lactic acid) films”, Polymer Degradation and Stability, v.95, n.8, pp 1292-1298, Aug. 2010.

[5] PAIVA, R.M.M., MARQUES, E. A. S., SILVA, L.F.M., et al., "Effect of the surface treatment in polyurethane and natural leather for the footwear industry", Materwiss Werkstofftech, v.46, n.1, pp 47-58, Jan. 2015.

[6] PAIVA, R.M, MARQUES, E.A, SILVA, L.F., et al., "Importance of the surface treatment in the peeling strength of joints for the shoes industry", Apply. Adhesion Science, pp 1-5, Dec. 2013.

[7] FIORI R., Síntese e caracterização de poliuretano termoplástico contendo poss via extrusão reativa, Tese de D.Sc., Universidade Federal do Rio Grande do Sul, Rio Grande do Sul, RS, Brazil, 2011.

[8] ASSOCIAÇÃO BRASILEIRA DE NORMAS TÉCNICAS. ABNT NBR 10456, Adesivos para calçados e correlatos, Determinação da resistência da colagem, 2012.

[9] PEACOCK A. Handbook of polyethylene: structures: properties, and applications. 1st ed. New York, Marcel Dekker, 2000.

[10] FERRAGE, E., MARTIN, F., BOUDET, A., et al., "Talc as nucleating agent of polypropylene: morphology induced by lamellar particles addition and interface mineral-matrix modelization”, Journal Mater, v.37, n. 8, pp 1561-1573, April, 2002. 
[11] MORALES, A.R., PAIVA, L.B., ZATTARELLI, D. "Morphology, Structure and Mechanical Properties of Polypropylene Modified with Organophilic Montmorillonite", Polímeros, v. 22, n.1 pp 54-60, 2012.

[12] SHIOMI, T., TSUKADA, H., TAKESHITA, H., et al., "Crystallization of semicrystalline block copolymers containing a glassy amorphous component”, Polymer (Guildf), v. 42, pp 4997-5004, 2001.

[13] LANFRANCONI, M.R., ALVAREZ, V.A, PEREZ, C.J. "Isothermal crystallization of gamma irradiated LDPE in the presence of oxygen", Radiation Physics and Chemistry, v.111, pp 74-80, Feb. 2015.

[14] CHEN, J., WANG, X., LIU, W. "Crystallization kinetics of polyethylene/paraffin oil blend sheets formed by thermally induced phase separation with different molecular weights of polyethylene", Journal Thermal Analytical Calorimetry, v. 118, n. 3, pp1649-1661, Dec. 2014.

[15] PISTOR, V., CONTO, D., ORNAGHI, F. G., et al., "Microstructure and Crystallization Kinetics of Polyurethane Thermoplastics Containing Trisilanol Isobutyl POSS", Journal of Nanomaterials, pp 1-8, Feb. 2012.

[16] LORENZO, A.T., ARNAL, M.L., ALBUERNE, J., et al., "DSC isothermal polymer crystallization kinetics measurements and the use of the Avrami equation to fit the data: Guidelines to avoid common problems", Polymer Test, v. 26, n.2 pp 222-231, April, 2007.

[17] HWANG, J-J., HUANG, S-M., LIU, H-J., et al., "Crystallization kinetics of poly (L-lactic acid)/montmorillonite nanocomposites under isothermal crystallization condition", Journal Apply Polymer Science, v. 124, pp 2216-2226, 2012.

[18] DESHMUKH, G.S., PESHWE, D.R., PATHAK, S.U., et al., "Nonisothermal crystallization kinetics and melting behavior of poly(butylene terephthalate) and calcium carbonate nanocomposites", Thermochim Acta, v. 606, pp 66-76, March, 2015.

[19] CORRÊA, A.X. Avaliação da influência da degradação com peróxido nas propriedades de polipropileno randômico com eteno ou buteno. Dissertação de M.Sc., Universidade Federal do Rio Grande do Sul, Rio Grande do Sul, RS, Brazil, 2007.

[20] JIANG XL. "Effect of nucleating agents on crystallization kinetics of PET", Express Polym Lett, v. 1, n.4, pp 245-251, 2007.

[21] SILVA, R.P. Estudo morfológico e cinético de nanocompósitos de PP/TiO 2 obtidos a partir da mistura no estado fundido ou por método sol-gel in situ. Tese de D.Sc., Universidade Federal do Rio Grande do Sul, Rio Grande do Sul, RS, Brazil, 2013.

[22] LEVY, J.F. An update on crosslinking of leather finishes with polycarbodiimide", In: Congress Florence, pp1-18, 2005. http://www.aaqtic.org.ar/congresos/florencia2005/ingles/lectures/alphabetical/USA.pdf (accessed August 20, 2015).

[23] DERKSEN, A. "Polycarbodiimides as Crosslinkers for Coatings", Lat. Am., Picassian Polymer, pp. 129, 2001.

[24] KUMAR, K.D., TSOU, A.H., BHOWMICK, A. K. "Facile one-pot synthesis and characterization of maleated hydrocarbon resin tackifier for improved adhesion", Institute Journal Adhesive and Adhesive, v. 30, n. 4, pp 200-7, June, 2010.

[25] ROMAN, M., ANDRIOLETTI, B., LEMAIRE, M., et al., "Investigations providing a plausible mechanism in the hexamethyldisilazane-catalyzed trimerization of alkyl isocyanates", Tetrahedron, v. 67, pp 15061510, Dec., 2011.

[26] ZHANG, S-L, WANG, G.B., JIANG, Z.H., et al., "Melting and crystallization behavior of PA1010/TPU blends", Journal Apply Polymer Science, v. 94, n.3, pp 839-844, August, 2004.

[27] AMICO, S.C., RIEGEL, I.C., PEZZIN, S.H., et al., "Efeito da incorporação de talco nas características térmicas, mecânicas e dinâmico-mecânicas de poliuretanos termoplásticos", Matéria (R.J.), v.16, n.1, pp 597-605, April, 2011. 